\title{
Modelong I.T.'S. S.H.O.W.T.I.M.E.: Mga kompensatoring estratehiya
}

Tosoc, Leunamatileme $\bigotimes$

Aklan State University, Philippines (leunamatileme.tosoc@asu.edu.ph)

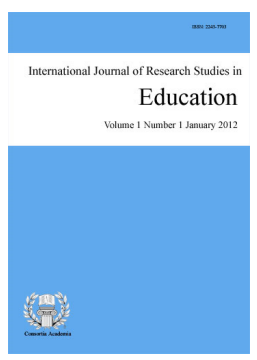

ISSN: 2243-7703 Online ISSN: 2243-7711

OPEN ACCESS

\section{Abstract}

This descriptive-correlational research was conducted to identify and evaluate compensatory strategies used by students taking up Bachelor of Technical-Vocational Teacher Education (BTVTEd) course at Aklan State University-College of Industrial Technology, Academic Year 2018-2019. Questionnaires were used for personal data, pictures for picture-cued storytelling and FGD while taking audio-video recordings to identify the compensatory strategies used by respondents. Respondents used compensatory strategies in expressing their ideas and thoughts which led the researcher develop the I.T.'S. S.H.O.W.T.I.M.E. Model towards learning Filipino. The model developed in this study can be used to further investigate the effectiveness of compensatory strategies across all courses.

Keywords: communicative competence, compensatory strategies, mother tongue, second language, Filipino 


\section{Modelong I.T.'S. S.H.O.W.T.I.M.E.: Mga kompensatoring estratehiya}

\section{Introduction}

Pangunahing layunin sa pagtuturo ng wika ang paglinang sa kakayahang komunikatibo ng mga estudyante, berbal at di-berbal. Ang pagkakaroon ng mga estudyante ng kakayahang bumuo at makilahok sa tuloy-tuloy na daloy ng pakikipagtalastasan, pati na rin upang maunawaan ang pananaw ng iba at maibahagi ang mga kaalaman ay ilan lamang sa mga pangunahing layunin sa pagkatuto ng pangalawang wika (W2).

Sa tuwing ang mga estudyante ay napapako sa kanilang pag-uusap o pakikipag-usap, sila ay naguguluhan sa pagbuo ng nilalaman ng kanilang mga ideya o nakararanas ng kahirapan sa pagpapahayag dahil sa kakulangan ng mahusay na paggamit ng wika at kung paano gamitin ito tungo sa mabisang pakikilahok sa klase. Ang mga sitwasyong ito ay nasasaksihan ng mga guro kapag ang mga mag-aaral ay biglang tumitigil sa pagsasalita sa pagkakataong may mga pagbigkas o mga talakayan sa klase. Umaasa ang mga mag-aaral na mahanap ang pinakamabisang terminolohiya at mga istruktura ng wika na magagamit. Ang mga mag-aaral ay maaaring humingi ng tulong mula sa mga kaklase o guro sa pamamagitan ng posibleng mga interbensiyon mula sa kanila.

Natuklasan sa isang pag-aaral (Manzano, 2018) na ipinapakita ng mga mag-aaral ang kanilang mga kahirapan sa komunikasyon sa pamamagitan ng mga gap marker. Kasama sa mga pananda na ito ang mga kilos o kumpas na nagpahiwatig ng problema sa pakikipag-usap ng mga mag-aaral tulad ng pagtingin sa guro, pagtuturo sa isang tiyak na detalye sa larawan, paghakbang, pag-iikot at pagkaway ng kamay, paglabas-pasok ng kamay sa bulsa, paglalaro sa ID at pagkakamot ng ulo.

Ang mga kompensatori na estratehiya sa komunikasyon ay tumutukoy sa mga estratehiya na ginagamit kapag nahihirapan sa pakikipag-usap ang mag-aaral gamit ang pangalawang wika (W2) dahil salat sa kakayahan na magkaroon ng mabisang paghahatid ng mga ideya. Higit sa lahat ito ay dahil sa hindi pagkakaroon ng epektibong wika o simbolo na magpapahayag ng mga ideyang nilalayon. Kaya ang mga estratehiya sa komunikasyon ay ginagamit kapag ang mga bagay ay nagiging mahirap tulad ng pangunang lunas para sa mga hindi inaasahang pangyayari. Ito ay nangangahulugan na ang mga estratehiya sa komunikasyon ay ginagamit ng mag-aaral kapag nakararanas ng suliranin sa pagpaparating ng mga ideya at saloobin. Pahihintulutan nito ang sarili na gumamit ng mga posibleng estratehiya kapag nahihirapan na at natitigil sa mabisang pakikipagkomunikasyon.

Maraming pag-aaral (Margolis, 2001; Rababah at Bulut, 2007; Tudy a Villasor, 2017; Mandasari at Oktaviani, 2018; Manzano, 2018) ang nagpatotoo na malaki ang kaugnayan ng paggamit ng mga kompensatori na estratehiya at kasanayang komunikatibo ng mag-aaral sa pagkatuto ng wika kaya't nilayon ng mananaliksik na tukuyin at tayain ang umiiral na mga kompensatori na estratehiya sa mga mag-aaral na kumukuha ng kursong Bachelor of Technical-Vocational Teacher Education (BTVTEd) sa Aklan State University-College of Industrial Technology, Taong Panuruan 2018-2019.

\subsection{Layunin ng pag-aaral}

Nilayon ng pag-aaral na ito na tukuyin at tayain ang mga kompensatori na estratehiya na ginagamit sa pagkatuto ng Filipino ng mga mag-aaral na kumukuha ng kursong Bachelor of Technical-Vocational Teacher Education (BTVTEd) ng Aklan State University-College of Industrial Technology, Taong Panuruan 2018-2019.

Tinitiyak ng pag-aaral na ito ang mga sumusunod:

$>$ personal na datos ng mga mag-aaral ayon sa hayskul na pinagtapusan, pribado, pampubliko, pangunahing wika, at marka sa Filipino 1; 
$>\quad$ kompensatori na estratehiya na ginagamit;

$>$ kaugnayan ng personal na datos at kompensatori sa estratehiyang ginagamit sa hayskul na pinagtapusan, pangunahing wika, at marka sa Filipino 1; at

$>\quad$ makabuo ng modelo ng mga gawaing pangklasrum.

\section{Metodolohiya}

Sa palarawang-korelasyonal na pag-aaral na ito ay tinitiyak at tinataya ang mga kompensatori na estratehiya na ginagamit ng mga mag-aaral sa unang taon sa kolehiyo na kumukuha ng kursong Bachelor of Technical-Vocational Teacher Education (BTVTEd) Taong Panuruan 2018-2019. Sila ay nagmula pa sa iba't ibang bayan ng Aklan at maging sa karatig-bayan nito. Sa kabuoan, ito ay binubuo ng walumpu't anim (86) na mag-aaral ngunit pasumalang pumili lamang ng apatnapu (40) na kalahok para sa pag-aaral na ito. Ninais din na tukuyin ang kaugnayan nito sa kanilang hayskul na pinagtapusan, pangunahing wika at marka sa Filipino 1.

Upang makalap ang mga kinailangang datos, inihanda ng mananaliksik ang mga sumusunod: (1) talatanungan para sa personal na datos ng mga kalahok (2) mga larawan para sa picture-cued story telling na gawain pati na rin ang rater's sheets; at (3) mga tanong para sa isinagawang focus group discussion (FGD) ng mga mag-aaral.

Sa unang bahagi ay gumamit ng talatanungan na dumaan sa balidasyon ng tatlong propesor sa Filipino. Ito ay naglalaman ng personal na datos ng mga kalahok ayon sa hayskul na pinagtapusan, pangunahing wika at ang marka sa Filipino 1. Upang matukoy ang mga kompensatori na estratehiyang ginagamit ng mga mag-aaral sa Filipino ay isinagawa ang picture-cued story telling ng mga napiling kalahok sa loob ng 1 hanggang 5 minuto at itinala naman ang mga ito ng raters sa nakahandang rater's sheet.

Ang rater's sheet ay naglalaman ng talahanayan ng kompensatori na estratehiya na hango sa balangkas ni Oxford (1990) at naglaan din ng espasyo para sa mga karagdagang kompensatoring estratehiya na napuna mula sa mga tagatugon. Ang mga kompensatoring estratehiya na ito ay ang mga sumusunod:

(1) bahagya o tuluyang pag-iwas sa usapan, tumutukoy sa estratehiyang ginagamit kapag ang mag-aaral ay nagsimula nang magsalita ngunit biglang huminto sapagkat maaaring nahihirapan na ito o nagdesisyon nang huwag nang magsalita upang matigil na ang usapan;

(2) paggamit ng pagliligoy o kasingkahulugan ng salita, ito ay ang paggamit ng ibang salita o parirala na may kasingkahulugan na angkop sa salita o parirala;

(3) paghingi ng tulong, ginagamit ito kapag ang mag-aaral ay ibig magtanong tungkol sa tama o eksaktong terminolohiya;

(4) paglikha ng mga salita, tumutukoy sa pagbuo ng mga bagong salita o terminolohiya;

(5) paglipat sa pangunahing wika $\left(\mathrm{W}_{2} \mathrm{~W}_{1}\right)$, paggamit ng pangunahing wika (W1) para sa terminolohiya sa pangalawang wika (W2);

(6) panggagaya, ito ay tumutukoy sa paggamit ng mga kumpas o di-berbal na estratehiya;

(7) pagpili ng paksa, ginagamit ito kapag ninais ng mag-aaral na magsalita tungkol sa paksa na alam nito; at

(8) pagsasaayos ng mensahe, ginagamit kapag ninanais ng mag-aaral na ipahayag ang mensahe sa isang katanggap-tanggap na alternatibo na konstruksiyon kung saan hindi pa kilala ang angkop na anyo o pagbuo ng salita o termino.

Sa ikatlong bahagi, ay nagsagawa ng focus group discussion (FGD) na binubuo ng tig-lilimang kalahok 
Tosoc, L.

upang tukuyin din ang mga kompensatori na estratehiyang ginagamit. Gumamit ng audio-video recording upang matiyak at mataya ang mga kompensatori na estratehiyang ginamit ng mga kalahok.

\section{Mga resulta at pagtalakay}

Batay sa nakalap na datos, natuklasan ang sumusunod:

1.1 Personal na Datos ng mga Mag-aaral Ayon sa Hayskul na Pinagtapusan. Sa kabuoang bilang na apatnapu (40) na mga tagatugon sa pag-aaral na ito, mas lamang ang mga kalahok na nakapagtapos sa pampublikong paaralan na may bilang na dalawampu't siyam (29) o pitumpu't dalawa at kalahating porsiyento (72.50\%). Samantala, ang mga kalahok lamang na nakapagtapos sa pribadong paaralan ay labing-isa (11) o dalawampu't pito at kalahating porsiyento $(27.50 \%)$.

\section{Talahanayan 1.1}

Personal na datos ng mga mag-aaral ayon sa hayskul na pinagtapusan

\begin{tabular}{|c|c|c|c|}
\hline Mga Pinagtapusan & Bilang ng Mag-aaral & Porsiyento $(\%)$ & Ranggo \\
\hline Pribado & & & \\
\hline Sectarian & 5 & 12.50 & 3 \\
\hline Non-sectarian & 6 & 15.00 & 2 \\
\hline Sub-total & 11 & 27.50 & \\
\hline Pampubliko & 29 & 72.50 & 1 \\
\hline Kabuoan & 40 & & \\
\hline Mode & 1 & Pampubliko & Pampubliko \\
\hline
\end{tabular}

1.2 Personal na Datos ng mga Mag-aaral Ayon sa Pangunahing Wika na Ginagamit o Mother Tongue. Karamihan sa mga tagatugon ay gumagamit ng wikang Akeanon na may bilang na tatlumpu't lima (35) o walumpu't pito at kalahating porsiyento (87.50\%). Tatlo (3) lamang sa mga tagatugon ang gumagamit ng wikang Kinaray-a na may katumbas na pito at kalahating porsiyento (7.50\%). Makikita rin na isa (1) o dalawa't kalahating porsiyento $(2.50 \%)$ lamang ng kabuoang bilang ng tagatugon ang gumagamit ng Hiligaynon at Tagalog bilang pangunahing wika.

\section{Talahanayan 1.2}

Personal na datos ng mga mag-aaral ayon sa pangunahing wika na ginagamit o mother tongue

\begin{tabular}{cccc}
\hline Wika & Bilang ng Mag-aaral & Porsiyento $(\%)$ & Ranggo \\
\hline Akeanon & 35 & 87.50 & 1 \\
Hiligaynon & 1 & 2.50 & 3 \\
Kinaray-a & 3 & 7.50 & 2 \\
Tagalog & 1 & 2.50 & 3 \\
Kabuoan & 40 & 100.00 & \\
\hline
\end{tabular}

1.3 Personal na Datos ng mga Mag-aaral Ayon sa Marka sa Filipino 1. Dalawampu't lima (25) o animnapu't dalawa at animnapung porsiyento (62.60\%) sa mga tagatugon ang nakakuha ng markang pinakamagaling (95 - 100). Labindalawa (12) o tatlumpung porsiyento (30\%) naman ang lubhang magaling (90 - 94) at tatlo (3) lamang o pito’t kalahating porsiyento (7.50\%) ang magaling (85 - 89) sa Filipino 1.

\section{Talahanayan 1.3}

Personal na datos ng mga mag-aaral ayon sa marka sa Filipino 1 semestre sa unang (2018-2019)

\begin{tabular}{|c|c|c|c|c|}
\hline \multicolumn{2}{|r|}{ Antas } & Bilang ng Mag-aaral & Porsiyento (\%) & Ranggo \\
\hline $95-100$ & (Pinakamagaling) & 25 & 62.50 & 1 \\
\hline $90-94$ & (Lubhang Magaling) & 12 & 30.00 & 2 \\
\hline $85-89$ & (Magaling) & 3 & 7.50 & 3 \\
\hline & Kabuoan & 40 & 100.00 & \\
\hline & Median & 95.00 & Pinakamagaling & \\
\hline
\end{tabular}

38 Consortia Academia Publishing (A partner of Network of Professional Researchers and Educators) 
Modelong I.T.'S. S.H.O.W.T.I.M.E.: Mga kompensatoring estratehiya

2.1 Mga Kompensatori na Estratehiyang Ginagamit ng mga Tagatugon sa Picture-Cued Story Telling. Natuklasan na apatnapu (40) na mga tagatugon ay isang daang porsiyento (100\%) na gumamit ng mga kompensatori na estratehiya tulad ng panggagaya, pagpili ng paksa at pagsasaayos ng mensahe.

\section{Talahanayan 2.1}

Mga kompensatori na estratehiya na ginagamit ayon sa paggamit ng picture-cued story telling

\begin{tabular}{lccc}
\hline \multicolumn{1}{c}{ Mga Estratehiyang Ginagamit } & $\begin{array}{c}\text { Bilang ng } \\
\text { Mag-aaral }\end{array}$ & Porsiyento(\%) & Ranggo \\
\hline Bahagya o tuluyang pag-iwas sa usapan & 15 & 37.50 & 6 \\
Paggamit ng pagliligoy o kasingkahulugan ng salita & 32 & 80.00 & 3 \\
Paghingi ng tulong & 20 & 50.00 & 4 \\
Paglikha ng mga salita & 19 & 47.50 & 5 \\
Paglipat sa pangunahing wika $\left(\mathrm{W}_{2} \rightarrow \mathrm{W}_{1}\right)$ & 38 & 95.00 & 2 \\
Panggagaya & 40 & 100.00 & 1 \\
Pagpili ng paksa & 40 & 100.00 & 1 \\
Pagsasaayos ng mensahe & 40 & 100.00 & 1 \\
\hline
\end{tabular}

Sa pananaliksik na ito, ang mga panggagaya o di-berbal na kumpas na ginamit ng mga kalahok ay itinala ng mananaliksik ayon sa pagkakasunod-sunod mula ulo hanggang paa: (1) paghawi ng buhok; (2) paghawak sa ilang bahagi ng katawan tulad ng ilong, tainga, labi, at dibdib; (3) pagtuturo sa larawan; (4) pagkakamot ng ulo; (5) pag-iikot ng mga kamay; (6) pagkaway ng mga kamay; (7) paglalapat ng dalawang kamay; (8) paglalaro sa ID; (9) pagpalalagatik ng mga daliri; (10) paghawak ng bolpen o panyo; (11) pamemeywang; (12) paghatak sa damit/pantalon; (13) paglabas-pasok ng kamay sa bulsa; (14) pag-atras-abante; (15) pag-eekis ng mga paa; at panghuli, (16) pagtitingkayad.

\section{Talahanayan 2.1.1}

Panggagaya na ginagamit ng mga mag-aaral bilang kompensatori na estratehiya sa picture-cued story telling

$$
\text { Paghawi ng buhok }
$$

Paghawak sa ilang bahagi ng katawan tulad ng ilong, labi at dibdib

-Pagtuturo sa larawan

Pagkakamot ng ulo

Pag-iikot ng mga kamay

Pagkaway ng mga kamay

Paglalapat ng dalawang kamay

-Paglalaro sa ID

-Pagpalalagatik ng mga daliri

Paghawak ng bolpen o panyo

aPamemeywang

Paghawak sa damit/pantaloon

Paglabas-pasok ng kamay sa bulsa

-Pag-atras-abante

-Pag-eekis ng mga paa

Pagtitingkayad

Leyenda: •pinakamadalas gamitin; - pinakabihirang gamitin.

Ayon kay Manzano (2018) ang mga gap markers ay nagpahiwatig ng kahirapan sa pakikipagkomunikasyon ng mga mag-aaral. Sa pag-aaral na ito, bagamat gumamit ang mga tagatugon ng mga di-berbal na kumpas at nagkaroon ng kunting kahirapan sa pagpapahayag, matagumpay na naitawid at naibahagi ang kanilang sariling pananaw at ideya tungkol sa mga ipinakitang mga larawan. Nagmistula itong pangunang lunas o first aid ng mga tagatugon bago pa man lubusang makahanap ng eksaktong salita o ideya na makapupuno at makakukumpleto sa pahayag.

Sa mga pangunang lunas na naitala ng mananaliksik, sumasang-ayon ito sa pag-aaral ni Manzano (2018) na ang pinakamadalas maobserbahan sa mga tagatugon habang nagsasagawa ng picture-cued story telling ay ang pagtuturo sa larawan upang mabigyan ng tuon at makabubuo ng tamang kaisipan ayon sa pagkakasunod-sunod 
Tosoc, L.

ng mga larawan. Ang pinakabihira naman na ipinamalas ng mga tagatugon ay ang pagkakamot ng ulo, paglalaro ng ID, pagpalalagatik ng daliri, pamemeywang at pag-atras-abante at pag-eekis ng mga paa. Ang mga natuklasan ni Manzano (2018) ay natagpuan din sa pag-aaral na ito.

Talahanayan 2.1.2

Paghahambing ng mga Kompensatori na Estratehiya nina Manzano (2018) at Tosoc (2019)

\begin{tabular}{|c|c|}
\hline MANZANO (2018) & TOSOC (2019) \\
\hline Pagtingin sa guro & Paghawi ng buhok \\
\hline $\begin{array}{l}\text { Pagtuturo sa isang partikuar na detalye } \\
\text { larawan }\end{array}$ & $\begin{array}{l}\text { Paghawak sa ilang bahagi ng katawan tulad ng ilong, labi at } \\
\text { dibdib }\end{array}$ \\
\hline Paghakbang & Pagtuturo sa larawan \\
\hline Pag-iikot ng mga kamay & Pagkakamot ng ulo \\
\hline Pagkaway ng mga kamay & Pag-iikot ng mga kamay \\
\hline Paglabas-pasok ng kamay sa bulsa & Pagkaway ng mga kamay \\
\hline Paglalaro sa ID & Paglalapat ng dalawang kamay \\
\hline \multirow[t]{9}{*}{ Pagkakamot ng ulo } & Paglalaro sa ID \\
\hline & Pagpapalagatik ng mga daliri \\
\hline & Paghawak ng bolpen o panyo \\
\hline & Pamemeywang \\
\hline & Paghawak sa damit/pantalon \\
\hline & Paglabas-pasok ng kamay sa bulsa \\
\hline & Pag-atras-abante \\
\hline & Pag-eekis ng mga paa \\
\hline & Pagtitingkayad \\
\hline
\end{tabular}

Makikita sa Talahanayan 2.1.2 ang paghahambing ng mga natuklasan ni Manzano (2018) at ng mananaliksik na mga panggagaya o kumpas na ginamit ng mga tagatugon bilang kompensatori na estratehiya sa pagsasagawa ng picture-cued storytelling. Bukod sa mga natuklasan na mga kumpas ni Manzano (2018) na malimit isagawa ng mga mag-aaral gamit ang ulo at upper extremities (mula balikat o pantaas na bahagi ng katawan) at paghakbang bilang bahagi naman ng lower extremity (bahagi ng katawan mula beywang pababa ng paa) ay nagkaroon ng mga karagdagang obserbasyon ang mananaliksik mula beywang hanggang paa ng mga tagatugon.

Ang pagpili ng paksa bilang kompensatori na estratehiya ay nagpapatunay lamang na ito ay nagbibigay kompiyansa sa sarili ng mga tagatugon upang maitawid nang maayos ang pagpapahayag o paglalarawan sa mga napiling paksa. Hindi ito nangangahulugan na wala silang alam sa mga paksang hindi napili kundi mas kampante lamang silang talakayin ang paksang batid nilang mairaraos nang mabuti at may kahusayan. Pinahihintulutan nito ang sariling makabuo ng pahayag na may layuning makapagbahagi ng sariling pananaw at kaalaman sa iba na maaaring naimpluwensiyahan ng sariling interes at motibasyon. Dagdag pa rito, ninais nilang talakayin ang paksang may kaugnayan sa kanilang pang-araw-araw na karanasan at ikawing sa kasalukuyang gawain.

Ang kompensatori na estratehiyang pagsasaayos ng mensahe ay napatunayan na isang buong porsiyento $(100 \%)$ na ginamit ng lahat ng mga tagatugon. Sa pag-aaral ni Mei at Nathalang (2010) ay pumapangatlo lamang ito sa pinakamadalas gamiting estratehiya ng mga kalahok. Marahil, totoong nakararanas ng kahirapan ang mga tagatugon sa pagbuo ng kanilang naunang pahayag, kung kaya't natitigil, nauutal at nagsisimulang muli na naiiba na sa naunang pahayag sapagkat naiimpluwensiyahan ng interlanguage o pagkakaiba-iba ng alam na wika. Sa pagkakataong ito, bukod sa paggamit ng pangunahing wika na Akeanon na may iba't iba rin na varyasyon at ng wikang Filipino na tinutukoy na pangalawang wika $\left(\mathrm{W}_{2}\right)$ sa pag-aaral na ito, ay madalas din na sumisingit o gumagamit ng wikang Ingles ang mga tagatugon sa pagpapahayag sa Filipino.

Siyamnapu't limang porsiyento (95\%) o tatlumpu't walo (38) naman sa mga tagatugon ang gumamit ng kompensatori na estratehiyang paglipat sa pangunahing wika $\left(\mathrm{W}_{2} \rightarrow \mathrm{W}_{1}\right)$. Pinapatunayan sa pananaliksik na ito na sadyang gumagamit ng estratehiya sa pakikipagkomunikasyon ang mga tagatugon dahil sa kakapusan ng magagamit na mapagkukunan ng wika. Tinitiyak lamang dito na hindi naisasagawa ang ninanais na mensahe tulad nang pagpapahayag gamit ang sariling wika o pangunahing wikang Akeanon ng mga tagatugon. Lumalabas din sa 
pag-aaral na ito na gumagamit ang mga tagatugon ng code-switching o pagpapalit-koda. Tulad nang mga napatunayan sa mga naunang pag-aaral (Tupas, 2014; Asuncion, 2010) na ang pagpapalit-koda ay isang mahalagang kasangkapan dahil may karaniwang lohika sa pagbabago ng mga wika. Naghahanap ang mga mag-aaral ng mapagkukunan ng wika na magagamit at tiyak na lubos naiintindihan ng mga tagapakinig. Kapwa kapaki-pakinabang ang paggamit nito sa tagapagsalita at tagapakinig. Sa tagapagsalita, hinahayaan nitong maging kampante sa pakikipagkomunikasyon at malayang maiparating ang saloobin sa kausap o tagapakinig. Nahahasa rin ang kakayahang komunikatibo nito sapagkat nagkakaroon ng pagkakataong pumili ng epektibong pahayag na siya namang tunay na layunin sa pakikipag-ugnayan sa kapwa. Tinutulungan din nito ang tagapakinig na unawain ang kahirapan sa pagpapahayag ng tagapagsalita at tanggapin na sa pamamagitan nito ay matagumpay na maitatawid at makukumpleto ang mga ideya na nais iparating sa kausap.

Ang paggamit ng pagliligoy o kasingkahulugan na salita ay ginamit ng tatlumpu't dalawang (32) tagatugon o walumpung posiyento (80\%) ng kabuoang bilang. Naghahagilap ng katumbas na salita ang mga tagatugon na panghalili o pamalit sa mga salitang naging sanhi ng kanilang kahirapan sa pagpapahayag. Hindi limitado ang kahulugan ng kompensatori na estratehiyang ito sa paghahanap ng panumbas na salita sa Filipino kundi maging sa wikang Ingles. Madalas na ginagamit na kasingkahulugan ng mga tagatugon ay ang katumbas ng mga salita sa wikang Ingles.

Singkwenta porsiyento (50\%) o dalawampu (20) naman sa mga tagatugon ang humingi ng tulong bilang kompensatori na estratehiya. Natuklasan sa pag-aaral na ito na kapag nahihirapan nang maglarawan ang mga tagatugon, napapahinto, at nauutal hanggang sa magbigay ng hudyat sa kaklase na nangangailangan na ito ng tulong. Ayon kay Oxford (1990) humihiling ng isang tao para sa tulong sa pamamagitan ng pag-aatubili o tahasang pagtatanong sa tao upang ibigay ang nawawalang pagpapahayag sa target na wika. Subalit sa pag-aaral ni Asuncion (2010), isa ito sa pinakabihirang ginagamit na kompensatori na estratehiya. Marahil, ang mga tagatugon ay hindi komportable sa paghingi ng tulong sa iba at nagtatangka pa rin na makayanan o mapunan ang limitasyon sa paglalarawan. Ngunit sa pananaliksik na ito, napatunayan na hindi nag-atubiling magbigay ng hudyat ang tagapagsalita kapag nahihirapan upang makakalap ng posibleng salita na makabubuo ng eksaktong pahayag. Paminsan-minsan, napuna ng mananaliksik na nasasabayan ang estratehiyang ito ng iba pang kompensatori na estratehiya habang isinasagawa tulad ng pag-iikot ng kamay, paghawak sa tiyak na bahagi ng katawan tulad ng ilong, tainga, labi, at dibdib.

Ang mga estratehiya na paglikha ng mga salita, at bahagya o tuluyang pag-iwas sa usapan ang nakakuha ng mas mababa sa limampung porsiyento (50\%) na maiuugnay rin sa naging resulta ng pananaliksik ni Asuncion (2010). Marahil, sinubukan pa rin ng lahat ng mga kalahok na makahanap ng panumbas nito sa wikang Filipino, wikang Akeanon at maging sa wikang Ingles at hindi na nakuhang makabuo pa ng mga bagong salita na makapagbibigay-linaw sa ideyang nais iparating sa tagapakinig.

Ang resulta ay nasasaad na ang mga kalahok ay kadalasang gumagamit ng panggagaya, pagpili ng paksa at pagsasaayos ng mensahe upang makabuo ng pahayag. Ibig sabihin ang ganitong pamamaraan ay higit na nakatutulong sa mga mag-aaral upang epektibo nilang maiparating ang ninanais na mensahe sa tagatanggap, gayundin, ang mapasigla ang interes at damdamin ng mga tagapakinig. Ito ang pamamaraan ng mga mag-aaral upang makabuo ng mga pahayag at malinang ang kakayahang komunikatibo, berbal o di-berbal.

2.2 Mga Kompensatori na Estratehiya na Ginagamit sa Focus Group Discussion. Natuklasan na ang madalas gamitin na mga kompensatori na estratehiya ng mga kalahok ay ang paglipat sa pangunahing wika $\left(W_{2}->W_{l}\right)$ at ang panggagaya. Lahat ng mga panggagaya na ipinamalas ng mga kalahok habang sinasagawa ang picture-cued story telling ay napuna rin habang sinasagawa ang focus group discussion at naidagdag pa rito ang pagbaba-taas ng paa sa legrest ng upuan at ang pangunguyakoy.

Sa Talahanayan 2.2, ipinapakita ang mga kompensatori na estratehiya na ginamit ng mga tagatugon sa gawaing focus group discussion (FGD). Pagkatapos masuri, natuklasan na ang madalas gamitin na mga kompensatori na estratehiya ng mga kalahok ay ang paglipat sa pangunahing wika $\left(\boldsymbol{W}_{2}->W_{l}\right)$ at ang 
Tosoc, L.

panggagaya.

Talahanayan 2.2

Mga kompensatori na estratehiya na ginagamit sa focus group discussion

\begin{tabular}{lccc}
\multicolumn{1}{c}{ Mga Estratehiyang Ginagamit } & $\begin{array}{c}\text { Bilang ng } \\
\text { Mag-aaral }\end{array}$ & $\begin{array}{c}\text { Porsiyento } \\
(\%)\end{array}$ & Ranggo \\
\hline Bahagya o tuluyang pag-iwas sa usapan & 7 & 17.50 & 5 \\
Paggamit ng pagliligoy o kasingkahulugan ng salita & 7 & 17.50 & 5 \\
Paghingi ng tulong & 28 & 70.00 & 4 \\
Paglikha ng mga salita & 7 & 17.50 & 5 \\
Paglipat sa pangunahing wika $\left(\mathrm{W}_{1}->\mathrm{W}_{2}\right)$ & 40 & 100.00 & 1 \\
Panggagaya & 40 & 100.00 & 1 \\
Pagpili ng paksa & 37 & 92.50 & 2 \\
Pagsasaayos ng mensahe & 32 & 80.00 & 3 \\
\hline
\end{tabular}

Sa pagsusuri ng mga naging tugon ng mga kalahok sa pananaliksik na ito, nagkaroon ng iba't ibang paraan upang magamit o lumipat mula sa wikang Filipino patungong wikang Akeanon. Ang ilan sa mga kalahok ay lumilipat sa pangunahing wika sa pamamagitan ng pagsasabi ng halos buong sagot sa pangunahing wika. Ngunit napagtanto ng mananaliksik na hindi ibig sabihin nito na nahirapan ang tagapagsalita sa paghagilap ng angkop na katumbas sa Filipino kundi kusa na lamang itong namutawi sa kalahok upang maiparating ang tunay na nararamdaman habang isinasagawa ang gawain. Lumilipat nang tuluyan sa pangunahing wika ang mga tagatugon upang mas maipaliwanag nang mabisa ang nararamdaman sa isinagawang gawain. Mababakas din ang punto sa pagsasalita ng wikang Akeanon ng mg kalahok.

Lahat ng mga tagatugon ay nagpamalas din ng paggamit ng panggagaya habang isinasagawa ang focus group discussion (FGD).

\section{Talahanayan 2.2.1}

Panggagaya na ginagamit ng mga mag-aaral bilang kompensatori na estratehiya sa focus group discussion

Paghawi ng buhok

Paghawak sa ilang bahagi ng katawan tulad ng ilong, labi at dibdib

Pagtuturo sa larawan

Pagkakamot ng ulo

Pag-iikot ng mga kamay

Pagkaway ng mga kamay

Paglalapat ng dalawang kamay

Paglalaro sa ID

Pagpapalagatik ng mga daliri

Paghawak ng bolpen o panyo

Pamemeywang

Paghawak sa damit/pantalon

Paglabas-pasok ng kamay sa bulsa

Pag-eekis ng mga paa

Pangunguyakoy

Pagtaas/baba ng paa sa leg rest ng upuan

Sa pagsasagawa ng focus group discussion (FGD), kinukumpirma sa Talahanayan 2.2.1 ang maraming beses na paggamit ng mga kompensatori na estratehiya ng mga tagatugon na ginamit din sa picture-cued story telling maliban sa pagtitingkayad ngunit nadagdagan din ito ng pangunguyakoy at pagtaas-baba ng paa sa leg rest $n g$ upuan habang nagsasalita. Ang iba pang kompensatori na estratehiya na ginamit ng mga kalahok ay ang pagpili ng paksa na ginamit ng tatlumpu't pito (37) o siyampu't dalawa at kalahating porsiyento (92.50\%) ng mga kalahok, pagsasaayos $n g$ mensahe na ginamit naman ng tatlumpu't dalawa (32) o walumpung porsiyento (80\%), at ang pahinging tulong na ipinamalas ng dalawampu't walo (28) o pitumpung porsiyento (70\%).

Ang iba pang kompensatori na estratehiyang natuklasang ginagamit ng mga tagatugon ay nagtala ng mas

42 Consortia Academia Publishing (A partner of Network of Professional Researchers and Educators) 
mababa na sa limampung porsiyento (50\%), tulad ng bahagya o tuluyang pag-iwas sa usapan, paggamit $n g$ paliligoy o kasingkahulugan ng salita, at ang paglikha ng mga salita na ginamit lamang ng pito (7) o labimpitu't kalahating porsiyento (17.50\%) lamang.

Sa kabuoan, mapapansin na ang mga kompensatori na estratehiyang karaniwang ginagamit ng mga mag-aaral sa BTVTEd ay ang paglipat sa pangunahing wika $\left(\mathrm{W}_{2}->\mathrm{W}_{1}\right)$ at panggagaya upang makabuo ng isang paksa. Marahil, ang mga mag-aaral sa kolehiyo ay nagkakaroon pa rin ng kakapusan sa paggamit ng wikang Filipino kahit sabihing may sapat na itong kahantaran upang maging bihasa sa paggamit nito lalo na sa layuning pangkomunikatibo. Kung kaya't napatunayan sa pag-aaral na ito na ang mga tagatugon ay mistulang nangangailangan ng mga paunang panlunas o first aid upang agarang masolusyunan ang kakapusan at kahirapan sa paghahatid ng mensahe upang magkaroon ng makabuluhang ugnayan sa kausap o tagapakinig.

3.1 Kaugnayan ng Hayskul na Pinagtapusan at Kompensatori na Estratehiya na Ginagamit. Batay sa mga datos, ang mga kompenstori na estratehiya na paggamit ng pagliligoy o kasingkahulugan ng salita $\mathbf{r}=$ $0.41^{\mathrm{ns}}, p=0.243$ at paglikha $\mathrm{ng}$ mga salita, $\mathrm{r}=0.57^{*}, p=0.011$ ay may katamtamang ugnayan ngunit ang huling nabanggit lamang ang nagbigay ng makabuluhang ugnayan sa hayskul na pinagtapusan ng mga mag-aaral.

\section{Talahanayan 3.1}

Kaugnayan ng hayskul na pinagtapusan at kompensatori na estratehiya na ginagamit

\begin{tabular}{|c|c|c|c|c|}
\hline Mga estratehiyang ginagamit & $\begin{array}{l}\text { Correlation } \\
\text { Coefficient }\end{array}$ & Interpretasyon & $p$-value & Deskripsiyon \\
\hline $\begin{array}{c}\text { Bahagya o tuluyang pag-iwas sa } \\
\text { usapan }\end{array}$ & $0.24^{n s}$ & Mababang ugnayan & 0.329 & Hindi Makabuluhan \\
\hline $\begin{array}{l}\text { Paggamit ng pagliligoy o } \\
\text { kasingkahulugan ng salita }\end{array}$ & $0.41^{n s}$ & Katamtamang ugnayan & 0.243 & Hindi Makabuluhan \\
\hline Paghingi ng tulong & $0.19^{n s}$ & Balewalang ugnayan & 0.923 & Makabuluhan \\
\hline Paglikha ng mga salita & $0.57 *$ & Katamtamang ugnayan & 0.011 & Hindi Makabuluhan \\
\hline $\begin{array}{c}\text { Paglipat sa pangunahing wika }\left(\mathrm{W}_{2}\right. \\
\left.->\mathrm{W}_{1}\right)\end{array}$ & $0.29^{n s}$ & Mababang ugnayan & 0.507 & Hindi Makabuluhan \\
\hline Panggagaya & $0.28^{n s}$ & Mababang ugnayan & 0.202 & Hindi Makabuluhan \\
\hline Pagpili ng paksa & $0.23^{n s}$ & Mababang ugnayan & 0.704 & Hindi Makabuluhan \\
\hline Pagsasaayos ng mensahe & $0.20^{n s}$ & Balewalang ugnayan & 0.650 & Hindi Makabuluhan \\
\hline
\end{tabular}

Ipinapakita sa Talahanayan 3.1 ang kaugnayan ng hayskul na pinagtapusan at kompensatori na estratehiyang ginagamit ng mga kalahok. Ayon sa resulta ng Pearson-r Product Moment Correlation, ang sumusunod na kompensatori na estratehiya na paghingi ng tulong, $\mathrm{r}=0.19^{\mathrm{ns}}, p=0.923$; at pagsasaayos $n g$ mensahe, $\mathrm{r}=0.20^{\mathrm{ns}}, p$ $=0.650$ ay maaaring bigyang-kahulugan na nagkaroon ng balewalang ugnayan. Samantala, ang estratehiyang bahagya o tuluyang pag-iwas sa usapan, $\mathrm{r}=0.24^{n s}, p=0.329$; paglipat sa pangunahing wika $\left(\mathrm{W}_{2} \mathrm{~W}_{1}\right), \mathrm{r}=0.29^{n s}, p$ $=0.507$; panggagaya na may $\mathrm{r}=0.28^{n s}, p=0.202$; at pagpili $n g$ paksa, $\mathrm{r}=0.23^{n s}, p=0.704$ ay maaaring ipakahulugan na may mababang ugnayan. Batay sa mga datos, ang mga kompenstori na estratehiya na paggamit ng pagliligoy o kasingkahulugan ng salita $\mathrm{r}=0.41^{n s}, p=0.243$ at paglikha $n$ g $\boldsymbol{\text { mga }}$ salita, $\mathbf{r}=\mathbf{0 . 5 7 *}, \boldsymbol{p}=\mathbf{0 . 0 1 1}$ ay may katamtamang ugnayan ngunit ang huling nabanggit lamang ang nagbigay ng makabuluhang ugnayan sa hayskul na pinagtapusan ng mga mag-aaral. Ang resulta ay nagpapatunay na ano man ang uri ng pinagtapusang hayskul ng mga kalahok, maging pampubliko o pribado man, hindi ito nakaaapekto sa kanilang paggamit ng mga kompensatori na estratehiyag nabanggit upang magkaroon ng mahusay at epektibong pakikilahok sa mga talakayan sa klase sa Filipino. Lahat ng mga estratehiyang ito ay maaaring gamitin upang makabuo ng mabisang pakikipagkomunikasyon sa loob ng klase. Ang paglikha ng mga salita bilang kompensatori na estratehiya ay likas lamang sa mga Akeanon na mag-aaral sapagkat marami silang mapagkukunan ng mga ideya hatid ng pagiging lantad ng mga ito sa iba't ibang wika na natatamo at nagagamit mula sa iba't ibang kausap at social media platforms.

3.2 Kaugnayan ng Pangunahing Wika o Mother Tongue at Kompensatori na Estratehiyang Ginagamit. 
Tosoc, L.

Ang kompensatori na estratehiyang pagsasaayos ng mensahe, $\mathbf{r}=\mathbf{0 . 4 7} \boldsymbol{*}, \boldsymbol{p}=\mathbf{0 . 0 0 2}$ ang tanging nagkaroon $\mathrm{ng}$ katamtaman at makabuluhang kaugnayan sa pangunahing wika ng mga mag-aaral.

\section{Talahanayan 3.2}

Kaugnayan ng pangunahing wika o mother tongue at kompensatori na estratehiyang ginagamit

\begin{tabular}{|c|c|c|c|c|}
\hline Mga estratehiyang ginagamit & $\begin{array}{l}\text { Correlation } \\
\text { Coefficient }\end{array}$ & Interpretasyon & $p$-value & Deskripsiyon \\
\hline $\begin{array}{l}\text { Bahagya o tuluyang pag-iwas sa } \\
\text { usapan }\end{array}$ & $0.19^{n s}$ & Balewalang ugnayan & 0.814 & Hindi Makabuluhan \\
\hline $\begin{array}{l}\text { Paggamit ng pagliligoy o } \\
\text { kasingkahulugan ng salita }\end{array}$ & $0.37^{n s}$ & Mababang ugnayan & 0.340 & Hindi Makabuluhan \\
\hline Paghingi ng tulong & $0.23^{n s}$ & Mababang ugnayan & 0.971 & Hindi Makabuluhan \\
\hline Paglikha ng mga salita & $0.38^{n s}$ & Mababang ugnayan & 0.126 & Hindi Makabuluhan \\
\hline $\begin{array}{l}\text { Paglipat sa pangunahing wika } \\
\left(\mathrm{W}_{2}->\mathrm{W}_{1}\right)\end{array}$ & $0.38^{n s}$ & Mababang ugnayan & 0.149 & Hindi Makabuluhan \\
\hline Panggagaya & $0.23^{n s}$ & Mababang ugnayan & 0.624 & Hindi Makabuluhan \\
\hline Pagpili ng paksa & $0.22^{n s}$ & Mababang ugnayan & 0.922 & Hindi Makabuluhan \\
\hline Pagsasaayos ng mensahe & $0.47 *$ & Katamtamang ugnayan & 0.002 & Makabuluhan \\
\hline
\end{tabular}

Ang Talahanayan 3.2 ay nagpapakita na ang kompensatori na estratehiyang bahagya o tuluyang pag-iwas sa usapan, $\mathrm{r}=0.19^{n s}, p=0.814$ ay hindi nagkaroon $\mathrm{ng}$ balewalang ugnayan o makabuluhang ugnayan sa pangunahing wika ng mga mag-aaral. Samantala, ang paggamit ng pagliligoy o kasingkahulugan ng salita, $\mathrm{r}=0.37^{n s}, p=0.340$; paghingi ng tulong, $\mathrm{r}=0.23^{n s}, p=0.971$; paglikha ng mga salita, $\mathrm{r}=0.38^{n s}, p=0.126$; paglipat sa pangunahing wika $\left(W_{2}->W_{l}\right), \mathrm{r}=0.38^{n s}, p=0.149$; panggagaya, $\mathrm{r}=0.23^{n s}, p=0.624$; at pagpili ng paksa, $\mathrm{r}=0.22^{n s}, p=0.922$; ay nagkaroon ng katumbas na mababang ugnayan at nangangahulugan na ang pangunahing wika o mother tongue ay walang makabuluhang kaugnayan sa ginagamit na mga estratehiyang nabanggit ng mga kalahok sa pakikipagkomunikasyon. Ang kompensatori na estratehiyang pagsasaayos ng mensahe, $\mathbf{r}=0.47 * \boldsymbol{p}=0.002$ ang tanging nagkaroon ng katamtaman at makabuluhang kaugnayan sa pangunahing wika ng mga mag-aaral. Ibig ipahiwatig na ano man ang wikang ginagisnan ng mga kalahok ay maaaring maging pangunang lunas ang pagsasaayos $n g$ mensahe upang pansamantalang malunasan ang nararanasang kahirapan o kakapusan sa pakikipagkomunikasyon nang tuluyang makilahok at makabuo ng pahayag sa pakikipagtalakayan sa klase sa Filipino. Hindi basehan ang kinamulatang wika ng mga kalahok maging ito ay Akeanon, Kinaray-a, Hiligaynon o Tagalog upang malampasan ang limitasyon sa pagbuo ng mabisang talakayan. Sinisikap ng mga mag-aaral na ayusin ang pagpapahayag upang magkaroon ng mabisang paghahatid ng mensahe.

3.3 Kaugnayan ng Marka sa Filipino 1 at Kompensatori na Estratehiyang Ginagamit. Ang resulta ng pagsusuri ay nagpapakita na ang pagpili ng paksa bilang kompensatori na estratehiya ay nagkaroon ng mababa ngunit may makabuluhang kaugnayan sa nakuhang grado sa Filipino 1 ng mga mag-aaral.

\section{Talahanayan 3.3}

Kaugnayan ng marka sa Filipino 1 at kompensatori na estratehiyang ginagamit

\begin{tabular}{|c|c|c|c|c|}
\hline Mga estratehiyang ginagamit & $\begin{array}{l}\text { Correlation } \\
\text { Coefficient }\end{array}$ & Interpretasyon & $p$ - value & Deskripsiyon \\
\hline $\begin{array}{l}\text { Bahagya o tuluyang pag-iwas sa } \\
\text { usapan }\end{array}$ & $0.05 \mathrm{~ns}$ & Balewalang ugnayan & 0.765 & Hindi Makabuluhan \\
\hline $\begin{array}{l}\text { Paggamit ng pagliligoy o } \\
\text { kasingkahulugan ng salita }\end{array}$ & $-0.16^{\mathrm{ns}}$ & Balewalang ugnayan & 0.337 & Hindi Makabuluhan \\
\hline Paghingi ng tulong & $0.18^{\mathrm{ns}}$ & Balewalang ugnayan & 0.262 & Hindi Makabuluhan \\
\hline Paglikha ng mga salita & $0.16^{\mathrm{ns}}$ & Balewalang ugnayan & 0.338 & Hindi Makabuluhan \\
\hline $\begin{array}{l}\text { Paglipat sa pangunahing wika } \\
\text { (W2 -> W1) }\end{array}$ & $-0.04^{\mathrm{ns}}$ & Balewalang ugnayan & 0.802 & Hindi Makabuluhan \\
\hline Panggagaya & $-0.27^{\mathrm{ns}}$ & Mababang ugnayan & 0.090 & Hindi Makabuluhan \\
\hline Pagpili ng paksa & $-0.33 *$ & Mababang ugnayan & 0.039 & Makabuluhan \\
\hline Pagsasaayos ng mensahe & $0.20^{\mathrm{ns}}$ & Balewalang ugnayan & 0.216 & Hindi Makabuluhan \\
\hline
\end{tabular}

44 Consortia Academia Publishing (A partner of Network of Professional Researchers and Educators) 
Sa Talahanayan 3.3, mapapansin na ang lahat ng kompensatori na estratehiya ay hindi makabuluhan maliban sa pagpili ng paksa na may $\mathrm{r}=0.33^{*}, \mathrm{p}=0.039$. Ang resulta ng pagsusuri ay nagpapakita na ang pagpili ng paksa bilang kompensatori na estratehiya ay nagkaroon ng mababa ngunit may makabuluhang kaugnayan sa nakuhang grado sa Filipino 1 ng mga mag-aaral. Marahil, nagpamalas ang mga tagatugon ng mas mayaman na ideya o impormasyon hinggil sa mga paksang alam nila at kampanteng mailalahad at maibabahagi sa klase. Ninais ng mga ito na talakayin ang mga paksang may kaugnayan sa kanilang pang-araw-araw na buhay bilang mag-aaral at indibidwal. Sa tatlong pinagpiliang mga larawan, ang Museo, Regalo at Bus, mas madalas na inilarawan ng mga kalahok ang dalawang nahuling binanggit. Marahil ay sariwa pa sa gunita ng mga mag-aaral ang mga pangyayari nang nakaraang Pasko at ang larawan ng bus naman ay naiuugnay sa karanasan ng mga mag-aaral na madalas bumiyahe at sumasakay ng bus patungong paaralan kung kaya't nakabubuo kaagad sila ng mga ideya at nakalilikha ng mga kaisipan na nagmumula sa kanilang interes, motibasyon at karanasan.

\section{Kongklusyon at Rekomendayon}

Batay sa mga natuklasan sa pananaliksik na ito, ang mga sumusunod ang naging kongklusyon:

1. Ang mga tagatugon ay nakapagtapos ng hayskul sa pampublikong paaralan, ang pangunahing wika na ginagamit ay Akeanon, at nasa antas na may "pinakamagaling” na marka sa Filipino 1.

2. Sa picture-cued storytelling ginagamit ang panggagaya, pagpili ng paksa, at pagsasaayos ng mensahe. Sa focus group discussion (FGD) ay malimit gamitin ang paglipat sa pangunahing wika (W2 -> W1) at ang panggagaya. Ang mga estratehiya ay higit na nakatutulong sa mga mag-aaral upang madali nilang maihatid ang mga mensahe na gusto nilang ipaabot sa tagapakinig o tagatanggap nito.

3. Hindi man lahat ng mga kompensatori na estratehiya ay nagkaroon ng makabuluhang kaugnayan sa personal na datos ng mga mag-aaral, natuklasan naman sa pag-aaral na ito na lahat ng tagatugon ay gumagamit ng isa o higit pang kompensatori na estratehiya sa pagpapahayag ng kanilang mga ideya at kaisipan sa mga gawaing pasalita sa loob ng klasrum.

Nang matukoy ang kahalagahan ng mga kompensatori na estratehiyang ginagamit ng mga mag-aaral, madalas man o hindi ang paggamit ng mga ito, ang mananaliksik ay nakabuo ng isang modelo ng mga gawaing pangklasrum na pinapaniwalaang magiging makabuluhan para sa mga mag-aaral sa pamamagitan ng pakikilahok sa klase na may kalayaang ipahayag ang mga sariling kaalaman, interes at kagustuhang ibahagi ang mga ito sa ibang tagapakinig. Sa pamamagitan ng I.T.'S. S.H.O.W.T.I.M.E. na modelo ng mga gawaing pangklasrum, hinihikayat ang kalayaang lumahok nang may buong kapasiyahan, interes at kompiyansa sa sarili gamit ang mga kompensatori na estratehiya upang maipahayag nang maayos at malinaw ang ideya at saloobin.

$\boldsymbol{I}$ - Iove $\boldsymbol{T V}$ - Layunin nitong makapagbahagi ng ideya at saloobin tungkol sa isang paboritong programang pantelebisyon. Pipili ng paboritong programa sa telebisyon. Gagawa ng buod at ipahayag sa klase ang mga nabuong ideya at saloobin tungkol sa naibigang palabas.

T - alk Vernacular - Layunin nitong makapagpahayag ang mga mag-aaral gamit ang pangunahing wika o Akeanon. Maghahanap ng isang pahayagan/magasin o anumang babasahin na nakasulat sa wikang Akeanon at pipili lamang ng isang balita o paksa at iuulat ito sa harap ng klase.

S - how and Share - Layunin ng gawaing ito na malinang ang kakayahan ng mga mag-aaral sa pagtaguyod ng mga produktong Aklanon at manghikayat ng mga mamimili/turista. Pipili ng kahit na anong produktong Aklanon at ibabahagi sa klase kung bakit ito ang napili at ano ang mga magagandang katangian nito upang makahikayat pa ng maraming mamimili.

S - elf-Talk in a Minute - Layunin nitong makapagpahayag ng sarili ang mag-aaral nang walang alinlangan. Bubunot ang mag-aaral ng index card na naglalaman ng magkakaibang sitwasyon tungkol sa sarili. Pagkatapos, 
Tosoc, L.

magpapahayag ito tungkol sa nabunot na sitwasyon sa loob lamang ng isang munuto.

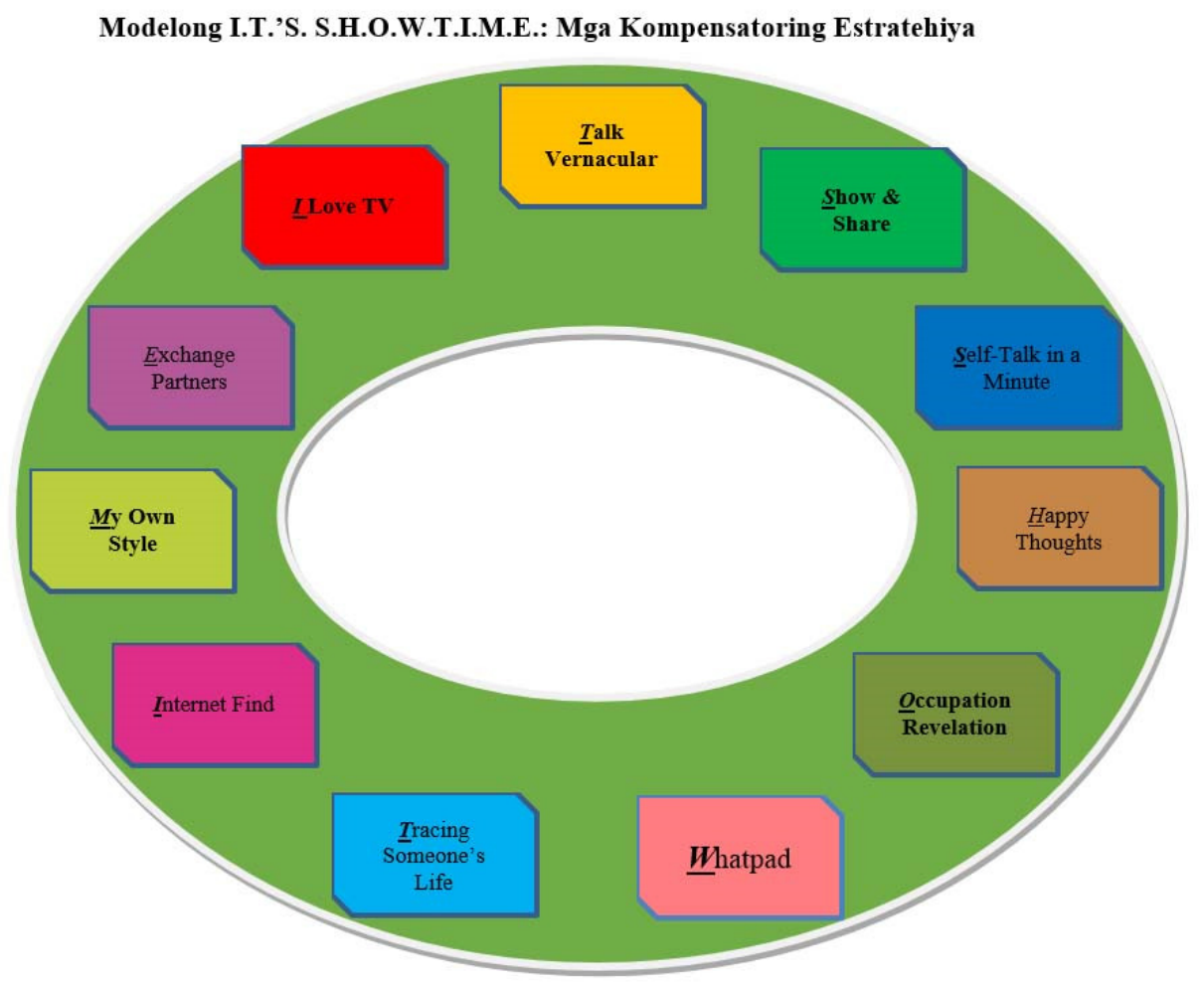

H - appy Thoughts - Layunin niong makapagpahayag ng isang masayang karanasan sa buhay. Ang mag-aaral ay magbabahagi ng isang masayang pangyayari sa buhay sa harap ng guro at mga kaklase.

$\boldsymbol{O}$ - ccupation Revelation - Layunin nitong mahubog ang mga katangian tungo sa isang pinapangarap na propesiyon at makapagbunyag ng mga saloobin at pangarap sa buhay. Magsusulat ng mga salita na may kaugnayan sa gustong propesiyon sa isang Manila paper. Pahuhulaan ito sa mga kaklase sa pamamagitan ng pagpapaliwanag ng mga nakasulat na salita. Saka pa lamang ilalabas ang larawan ng propesiyon na mapipili.

W- hatpad - Layuning nitong mahubog ang kakayahan sa pagbasa at malinang ang kakayahang kognitibo at komunikatibo sa pamamagitan ng pag-alala ng mga pangyayari sa nabasang kuwento sa wattpad. Magbabasa ng maikling kuwento sa wattpad at ibabahagi ito sa klase. Ilalarawan ang mga karakter at ibahagi ang gintong aral na mapupulot dito.

T- racing Someone's Life - Layunin ng gawaing ito na malinang ang kakayahang komunikatibo sa pamamagitan ng pagbabakas ng buhay ng isang mahalagang tao sa bawat mag-aaral. Mapapahalagahan ang mabubuting katangiang taglay ng iniidolong tao sa buhay. Magsasaliksik, makikipagpanayam o tutukoy ng isang tao na hinahangaan dahil sa mga katangiang taglay nito. Ibabahagi sa klase.

I-nternet Find - Layunin nitong mabuksan ang kaisipan sa mga makabagong teknolohiya o tuklas at magkaroon ng sapat na kamalayan sa mga nangyayari sa kapaligiran. Bibigyan ng isang gawain na mahahanap sa internet tungkol sa mga bagong tuklas sa buong mundo. Pag-aaralan ito at ibabahagi ang impormasiyong nakalap sa harap ng klase.

M-y Own Style - Mapupukaw ang kamalayan sa mga makabagong estilo sa maraming aspeto tulad ng fashion, hairstyle, at iba pa at maipamamalas ang pagsang-ayon o pagtutol tungkol dito. Magdadala ng larawan 
na magpapakita ng sariling estilo maging ito ay sa pananamit, gupit, kilos at gawi.

E- xchange Partners - Layunin nitong linangin sa bawat mag-aaral ang pagkakaroon ng tiwala na magbahagi ng mahahalagang kaalaman o damdamin sa kausap at hayaan itong ibahagi sa mga kaklase nang walang alinlangan. Maghahanap ng kapareha. Sa isang bond paper, magsusulat ng mga katanungan na nais itanong sa kapareha. Pagkatapos masagot ang mga ito, makikipagpalit ng kapareha sa susunod pang dalawang pares hanggang sa makakalap ng limang (5) katugunan mula sa mga ito. Kapag nagawa na, maaaring ibahagi sa klase ang nasaliksik mula sa mga kaklase.

Matapos ang masusing pagkalap ng mga kinailangang datos, nakabuo ang mananaliksik ng mga rekomendasyon na ito:

1. Maaaring magsagawa ng mga pananaliksik na nag-uugnay sa paggamit ng mga kompensatori na estratehiya at iba pang gawaing pasalita sa loob ng klasrum tulad ng debate, dula-dulaan, talumpati, pagbabalita, at pakikipanayam sa mga mag-aaral upang pagtibayin ang mga naisagawang pagsisiyasat. Maaari ding tukuyin ang iba't ibang ideya, pagpapahalaga, at reaksiyon ng mga kalahok gamit ang iba't iba pang mga baryabol tulad ng kasarian at kahantaran sa telebisyon at social media.

2. Pag-aralan ang ugnayan ng picture-cued storytelling at focus group discussion (FGD) bilang isang coaching strategy sa mga mag-aaral sa kolehiyo na maaaring maging angkop din sa iba pang mga estratehiya at kurso.

3. Maaaring gamitin ang modelo ni L.G. TOSOC (2019): I.T.'S. S.H.O.W.T.I.M.E. na nabuo sa pag-aaral na ito sa mga gawaing pangklasrum tungo sa paghubog ng kasanayang komunikatibo at pagkatuto ng Filipino sa lahat na kurso. Maaari ding baguhin ang materyal na gagamitin sa mga piling gawain tulad na lamang sa I-love $\mathrm{TV}$, maaaring gumamit ng ibang genre ng panitikan katulad ng paboritong pelikula, dula, maikling kuwento, dula, at marami pang iba.

\section{Mga sanggunian}

Asuncion, Z. S. (2010). Filipino college freshman student's oral compensatory strategies. The Philippine ESL Journal, 5.

Mandasari, B., \& Oktaviani, L. (2018). English language learning strategies: An exploratory study of management and engineering students. Premise: Journal of English Education and Applied Linguistics, 7(2). https://doi.org/10.24127/pj.v7i2.1581

Manzano, B. A. (2018). Examining the oral communication strategies used by a group of Nepalese adult learners .in an ESL context. The Southeast Asian Journal of English Language Studies, 24(1), 84-96. https://doi.org/10.17576/3L-2018-2401-07

Margolis, D. P. (2001). Compensation strategies by Korean students. The PAC Journal, 1, 163-174.

Mei, A., \& Nathalang S. (2010). Use of communication strategies by Chinese EFL learners. Chinese Journal of Applied Linguistics, 33(3), 110-125.

Oxford, R. L. (1990). Language learning strategies: What every teacher should know. Englewood Cliffs, NJ: Newbury House.

Oxford, R. L. (2003). Language learning styles and strategies: An overview. Gala, pp. 1-25. https://doi.org/10.1515/iral.2003.012

Rababah, A. G., \& Bulut, D. (2007). Compensatory strategies in Arabic as a second language. Poznan Studies in Contemporary Linguistics, 43(2), 83-106. https://doi.org/10.2478/v10010-007-0020-5

Tudy, I., \& Villasor, H. D. (2017). English language learning, strategy use and academic performance of college students. Slongan, 3(1), 30-47.

Tupas, T. F. (2004). Second language teaching. University of the Philippines Open University. 
Tosoc, L.

48 Consortia Academia Publishing (A partner of Network of Professional Researchers and Educators) 